\title{
Binding effect of proline-rich-proteins (PRPs) on in vitro antimicrobial activity of the flavonoids
}

\author{
Jawaad Ahmed Ansari ${ }^{1}$, Shahina Naz ${ }^{1}$, Omer Mukhtar Tarar ${ }^{2}$, Rahmanullah Siddiqi ${ }^{1}$, \\ Muhammad Samee Haider ${ }^{2}$, Khalid Jamil ${ }^{2}$ \\ ${ }^{1}$ Department of Food Science \& Technology, University of Karachi, Karachi, Pakistan. \\ ${ }^{2}$ Food Technology Section, Food and Marine Resources Research Centre, Laboratories Complex, \\ Karachi, Pakistan.
}

Submitted: March 12, 2013; Approved: June 6, 2014.

\begin{abstract}
The interaction of the cyanidin, pelargonidin, catechin, myrecetin and kaempferol with casein and gelatin, as proline rich proteins (PRPs), was studied. The binding constants calculated for both flavonoid-casein and flavonoid-gelatin were fairly large $\left(10^{5}-10^{7} \mathrm{M}^{-1}\right)$ indicating strong interaction. Due to higher proline content in gelatin, the binding constants of flavonoid-gelatin $\left(2.5 \times 10^{5}-6.2 \times\right.$ $\left.10^{7} \mathrm{M}^{-1}\right)$ were found to be higher than flavonoid-casein $\left(1.2 \times 10^{5}-5.0 \times 10^{7} \mathrm{M}^{-1}\right)$. All the flavonoids showed significant antibacterial activity against the tested strains. Significant loss in activity was observed due to the complexation with PRPs confirming that binding effectively reduced the concentration of the free flavonoids to be available for antibacterial activity. The decline in activity was corresponding to the values of the binding constants. Though the activities of free catechin and myrecetin were higher compared to pelargonidin, cyanidin and kaempferol yet the decline in activity of catechin and myrecetin due to complexation with casein and gelatin was more pronounced.
\end{abstract}

Key words: proline rich proteins, flavonoids, catechin, myrecetin, kaempferol, pelargonidin, cyanidin, gelatin, casein, binding constants.

\section{Introduction}

Polyphenols constitute one of the most numerous and ubiquitous groups of plant metabolites in all plant organs and thus are an integral part of both human and animal diets. Two reasons for the increasing interest of nutritionists, researchers and food manufacturers in polyphenols are (i) the recognition of their antioxidant properties and their potential utility in chemoprevention of various diseases associated with oxidative stress, such as cancer, cardiovascular and neurodegenerative diseases (Kuroda and Hara, 1999; Heim et al., 2002; Ramassamy, 2006; Ferrazzano et al., 2011) and (ii) their deleterious effects caused by their ability to bind and precipitate macromolecules, such as digestive enzymes, and also dietary proteins and carbohydrates, thereby modulating their digestibility (Hara and Honda, 1990; Charlton et al., 2002; Chauhan, 2007; He et al., 2007; McDougall et al., 2009; Zhang et al., 2010).
For a given polyphenolic structure, the ability to bind and precipitate different proteins may vary considerably. Likewise a protein molecule may show varying order of affinity for different polyphenols. The proline-rich proteins (PRPs) possess very strong affinity for polyphenols (Mehansho et al., 1987). This high relative affinity supports the formation of stable polyphenol - PRP complexes which may be crucial in preventing polyphenols from binding to digestive enzymes and food proteins (Hagerman and Butler, 1981; Lu and Bennick, 1998).

The proline rich proteins in food - gluten, gelatin and $\beta$-casein have been found to modulate the properties of polyphenols and cause changes in the nutritional status of the food (Kawai et al., 2003). Tea possesses strong antioxidant properties (Khan and Mukhtar, 2007), in vitro and in vivo, which are affected by addition of milk (Hasni et al., 2011). Similarly, consumption of dark chocolate rich in epicatechin, but not the milk chocolate, increases the anti- 
oxidant capacity of human blood plasma (Serafini et al., 2003).

Likewise the interaction of polyphenols with enzymes may significantly alter their activity, leading to change in expected energy that could be derived from a complex food and some other important consequences. For instance $\alpha$-amylase inhibitors isolated from wheat (Feng et al., 1996) and white bean (Carmona et al., 1996) significantly reduced the peak of postprandial glucose in healthy and type 2 diabetic subjects. Low molecular weight plantderived molecules such as luteolin, strawberry extracts, and green tea polyphenols have also been shown to inhibit $\alpha$-amylase or reduce postprandial hyperglycemia.

Antimicrobial and antioxidant activity of the polyphenols is well documented (Naz et al., 2006; Naz et al., 2007). The evaluation of antioxidant power of wine extracts revealed radical scavenging property with a good correlation between antioxidant activity and polyphenolic content values. The extracts also exhibited activity against a broad range of food-borne microorganisms (Tenore et al., 2011). The antimicobial activities of some tropical fruits including Grewia asiatica, and Carrisa carandas have been proved and associated to their polyphenolic compounds (Siddiqi et al., 2011). Also, the interactions of polyphenols with various proline rich proteins have been studied with reference to its probable role in sensation of astringency (Luck et al., 1994), altering antioxidant capacity of food (Arts et al., 2001), nutrient absorption and reducing enzyme inhibition (He et al., 2007). The effect of these interactions on the health benefits of polyphenols and on the properties and functions of the gluten, casein, and gelatin need to be more focused as neutraceutical claim for a food may drastically change due to these interactions. Among different subclasses of phenolic compounds, flavonoids have gained more attention as compared to others, the reason being diversity in structure, molecular weight, size, function and impact on health. In the present study, initially the interaction of various flavonoids with casein and gelatin was studied and then the effect of these interactions on the antimicrobial activity of the polyphenols was evaluated.

\section{Materials and Methods}

The flavonoids-catechin, myrecetin, pelargonidin, cyanidin and kaempferol were purchased from Sigma Chemical Co., while the casein and other chemicals were of reagent grade and used as supplied by Merck.

\section{Preparation of flavonoid-protein complexes}

$500 \mu \mathrm{g} / \mathrm{mL}$ solutions of both gelatin and casein in $0.1 \mathrm{M}$ potassium dihydrogen phosphate buffer were prepared. The protein concentration was determined spectrophotometrically using the extinction coefficients at $280 \mathrm{~nm}$ (Pace et al., 1995). The flavonoid solutions $(0.5-500 \mu \mathrm{g} / \mathrm{mL})$ prepared in $(20 / 80 \%)$ ethanol/water mix- ture were added dropwise to each of the proteins solution with constant stirring to achieve the final flavonoid concentrations of $0.25,2.5,25$ and $250 \mu \mathrm{g} / \mathrm{mL}$ and with a final protein concentration of $250 \mu \mathrm{g} / \mathrm{mL}$ (flavonoid/protein molar ratios of $0.001,0.01,0.1$ and 1 ). The $\mathrm{pH}$ of the solution was adjusted to 6.9-7.2 using Metler Toledo.

\section{Absorption spectroscopy}

The UV-Vis spectra of the flavonids and the above flavonoid-protein complexes (F-P complexes) were recorded on UV-Vis spectrophotometer and the values of the binding constants $\mathrm{K}$ were calculated as described (Stephanos, 1996; Zhong et al., 2004; Kanakis et al., 2006).

\section{Determination of antimicrobial activity}

Six different ATCC bacterial cultures were used to test the antimicrobial activity of the flavonids and F-P complexes. These cultures were maintained on Mueller Hinton agar medium at $4{ }^{\circ} \mathrm{C}$. The preparation of Mac Farland Turbidity Standard, preparation of inocula and its adjustment to 0.5 Mac Farland Standard $\left(10^{6}\right.$ colony forming units (CFU) per $\mathrm{mL}$ ), and antibacterial assay was followed as described (Siddiqi et al., 2011) except that for antibacterial assay $100 \mu \mathrm{L}$ of each of the flavonoid and F-P complex (in the flavonoid/protein molar ratio of 1) was used. Antibacterial effects of these were also compared with $100 \mu \mathrm{L}$ of the standard drugs - Ampicillin and Streptomycin (each $1 \mathrm{mg} / \mathrm{mL})$, as positive control and $(20 / 80 \%)$ ethanol/water mixture as negative control. Each assay in this experiment was performed in triplicate.

\section{Statistical analyses}

All of the experiments were performed in triplicate, and the data were expressed as the mean \pm SEM. Effect of binding of gelatin and casein on the antibacterial activity of the flavonoids was analyzed for significant differences using one-way analysis of variation (ANOVA) followed by a Bonferroni test for multiple comparisons using Originlab 8.0.

\section{Results and Discussion}

All flavonoids displayed substantial antibacterial activity against all the Gram-positive and Gram-negative ATCC strains (Table 1). The activity of the fractions was higher against Gram-positive strains than Gram-negative, the reason being the presence of an additional layer of lipid in the cell wall of Gram-negative strains which acts as permeability barrier and reduces the uptake of the fractions in the cell.

For a given bacterial strain, the difference in the antibacterial activity of the fractions was quite significant $(p<0.05)$ except between catechin and myrecetin, the order being catechin $>$ myrecetin $>$ kaempferol $>$ pelargonidin $>$ cyanindin. The difference in activity of the flavonoids due 
to structural variations has already been worked in several previous studies (Naz et al., 2006; Naz et al., 2007; Siddiqi et al., 2011). The relative activity difference is mainly concerned with the degree of hydroxylation, nature of substituent groups attached to B and/or C ring and their hydrophilicity or charged structure determining their ability to access the bacterial membranes. In contrast to gram positive bacteria, the cell wall of Gram-negative species contains lipopolysaccharides (which repels hydrophobic compounds) and a unique protein called porin which does not allow the migration of large hydrophobic molecules.

The higher antibacterial activity of catechin (a flavanol) compared to myrecetin and kaempferol flavonols) is attributed to their fact that higher degree of hydroxylation (Waterhouse, 2001) and the least activity of the anthocyanins (cyanidin and pelargonidin) among the three classes of flavonoids may be attributed to their positively charged oxygen, making them inaccessible to the lipophilic cell membranes of gram positive species. Also the porin is selective to small hydrophilic molecules and ions (Figure 1).

Significant loss in activity was observed $(p<0.05)$ due to the complexation with casein and gelatin confirming that strong binding with these proteins effectively reduced the concentration of the free flavonoids to be available for antibacterial activity. The decline in activity due to complexation which has been demonstrated by the decline in in- hibition zone of the free flavonoids (Table 1) was corresponding to the values of the binding constants of the complexes.

The UV spectra and values of binding constants for flavonoid complexes with casein and gelatin are depicted in Figure 2 and Table 2 respectively. The binding constants were fairly large indicating a strong interaction/affinity of flavonoids with these proteins. The values were higher than those calculated for flavonoid-HAS complexes (Kanakis et al., 2006) supporting stronger interaction of flavonoids with PRPs than with non PRPs. The binding constants of flavonoid-gelatin complexes were found to be higher than flavonoid-casein complexes (Table 2) which may be explained on the basis of higher $\%$ proline $(16 \%)$ in gelatin compared to casein $(\sim 1.7 \%)$. This extraordinary binding ability of PRPs like casein and gelatin is assumed to be associated with restricted mobility of proline in them and therefore relatively low entropy even before binding. Thus binding leads to a small change in entropy and overall greater binding energy. In addition to this, proline has a large flat hydrophobic surface which makes it a very good ligand for other hydrophobic surfaces such as aromatic rings of polyphenols (Williamson, 1994).

The higher binding constants of complexes with cyanidin compared to pelargonidin relates to the higher degree of hydroxylation in B ring of cyanidin and so of the myrecetin as compared to kaempferol. Besides the fact that<smiles>Oc1ccc(-c2[o+]c3cc(O)cc(O)c3cc2O)cc1</smiles><smiles>Oc1cc(O)c2cc(O)c(-c3ccc(O)c(O)c3)[o+]c2c1</smiles><smiles>Oc1cc(O)c2c(c1)O[C@H](c1ccc(O)c(O)c1)[C@H](O)C2</smiles><smiles>O=c1c(O)c(-c2cc(O)c(O)c(O)c2)oc2cc(O)cc(O)c12</smiles><smiles>O=c1c(O)c(-c2ccc(O)cc2)oc2cc(O)cc(O)c12</smiles>
kaempferol

Myrecetin

Figure 1 - The higher antibacterial activity of catechin (a flavanol) compared to myrecetin and kaempferol flavonols) is attributed to their fact that higher degree of hydroxylation (Waterhouse, 2001) and the least activity of the anthocyanins (cyanidin and pelargonidin) among the three classes of flavonoids may be attributed to their positively charged oxygen, making them inaccessible to the lipophilic cell membranes of gram positive species. 
Table 1 - Antibacterial activity of the Flavonoid and flavonoid-protein complexes at flavonoid concentration of $250 \mu \mathrm{g} / \mathrm{mL}$ and flavonoid to protein ratio of $1: 1$.

\begin{tabular}{|c|c|c|c|c|c|c|}
\hline \multirow[b]{2}{*}{ Flavonoid/complexes } & \multicolumn{6}{|c|}{ Zone of inhibition (mm) } \\
\hline & B.subtilis & S.aureus & C.botulinum & E.coli & P.aeruginosa & S.typhi \\
\hline $\mathrm{Cy}^{1 \mathrm{a}}$ & $15 \pm 0.80$ & $17 \pm 0.80$ & $13 \pm 0.45$ & $12 \pm 0.23$ & $10 \pm 0.11$ & $12 \pm 0.10$ \\
\hline $\mathrm{Cy}-\mathrm{C}^{1 \mathrm{~b}}$ & $8 \pm 0.45^{*}$ & $7 \pm 1.02^{*}$ & $9 \pm 1.00$ & $7 \pm 0.45^{*}$ & $8 \pm 1.00^{*}$ & $7 \pm 0.28^{*}$ \\
\hline $\mathrm{Cy}-\mathrm{G}^{1 \mathrm{c}}$ & $8 \pm 0.78^{*}$ & $7 \pm 0.56^{*}$ & $7 \pm 0.75$ & $7 \pm 0.50^{*}$ & $7 \pm 0.60^{*}$ & $8 \pm 0.34^{*}$ \\
\hline $\mathrm{Pg}^{2 \mathrm{a}}$ & $20 \pm 0.34$ & $22 \pm 0.21$ & $18 \pm 0.55$ & $17 \pm 0.28$ & $16 \pm 1.2$ & $18 \pm 0.45$ \\
\hline $\mathrm{Pg}-\mathrm{C}^{2 \mathrm{~b}}$ & $15 \pm 1.7$ & $15 \pm 1.01$ & $13 \pm 0.23$ & $12 \pm 0.55$ & $11 \pm 0.80$ & $12 \pm 0.43$ \\
\hline $\mathrm{Pg}-\mathrm{G}^{2 \mathrm{c}}$ & $8 \pm 0.54$ & $7 \pm 1.04$ & $8 \pm 0.56$ & $8 \pm 0.45$ & $8 \pm 0.34$ & $8 \pm 0.34$ \\
\hline $\mathrm{Ct}^{3 \mathrm{a}}$ & $34 \pm 0.60$ & $32 \pm 0.45$ & $31 \pm 0.60$ & $29 \pm 0.28$ & $28 \pm 0.25$ & $30 \pm 0.78$ \\
\hline $\mathrm{Ct}-\mathrm{C}^{3 \mathrm{~b}}$ & $26 \pm 0.78$ & $25 \pm 0.98$ & $22 \pm 0.90$ & $20 \pm 1.2$ & $19 \pm 1.0$ & $18 \pm 1.1$ \\
\hline $\mathrm{Ct}-\mathrm{G}^{3 \mathrm{c}}$ & $17 \pm 1.0$ & $14 \pm 1.2$ & $12 \pm 1.0$ & $12 \pm 1.0$ & $10 \pm 1.0$ & $9 \pm 1.2$ \\
\hline $\mathrm{My}^{4 \mathrm{a}}$ & $30 \pm 0.5$ & $30 \pm 0.8$ & $29 \pm 0.50$ & $28 \pm 0.56$ & $25 \pm 0.57$ & $28 \pm 0.50$ \\
\hline $\mathrm{My}-\mathrm{G}^{4 \mathrm{c}}$ & $12 \pm 1.0$ & $11 \pm 1.01$ & $10 \pm 0.44$ & $10 \pm 0.9$ & $9 \pm 0.22$ & $12 \pm 0.55$ \\
\hline $\mathrm{Ka}^{5 \mathrm{a}}$ & $25 \pm 1.2$ & $26 \pm 1.5$ & $25 \pm 1.0$ & $22 \pm 1.2$ & $21 \pm 1.5$ & $23 \pm 0.9$ \\
\hline $\mathrm{Ka}-\mathrm{C}^{5 \mathrm{~b}}$ & $15 \pm 1.5$ & $16 \pm 1.8$ & $14 \pm 1.0$ & $16 \pm 1.5$ & $14 \pm 0.49$ & $15 \pm 0.5$ \\
\hline $\mathrm{Ka}-\mathrm{G}^{5 \mathrm{c}}$ & $10 \pm 0.66$ & $9 \pm 0.76$ & $7 \pm 0.59$ & $9 \pm 0.9$ & $8 \pm 0.65$ & $8 \pm 0.44$ \\
\hline
\end{tabular}

Cy(cyanidin), Pg(pelargonidin), Ct(catechin), My(myrecetin), Ka(kaempferol), -C (casein complex, -G(Gelatin complex).

Data were expressed as mean \pm standard deviation of 3 replicates. For each flavonid the differences in values between the columns a,b and $\mathrm{c}$ were significant $(\mathrm{p}<0.05)$ except between $1 \mathrm{~b}$ and Ic where $(*)$ indicates no significant difference.
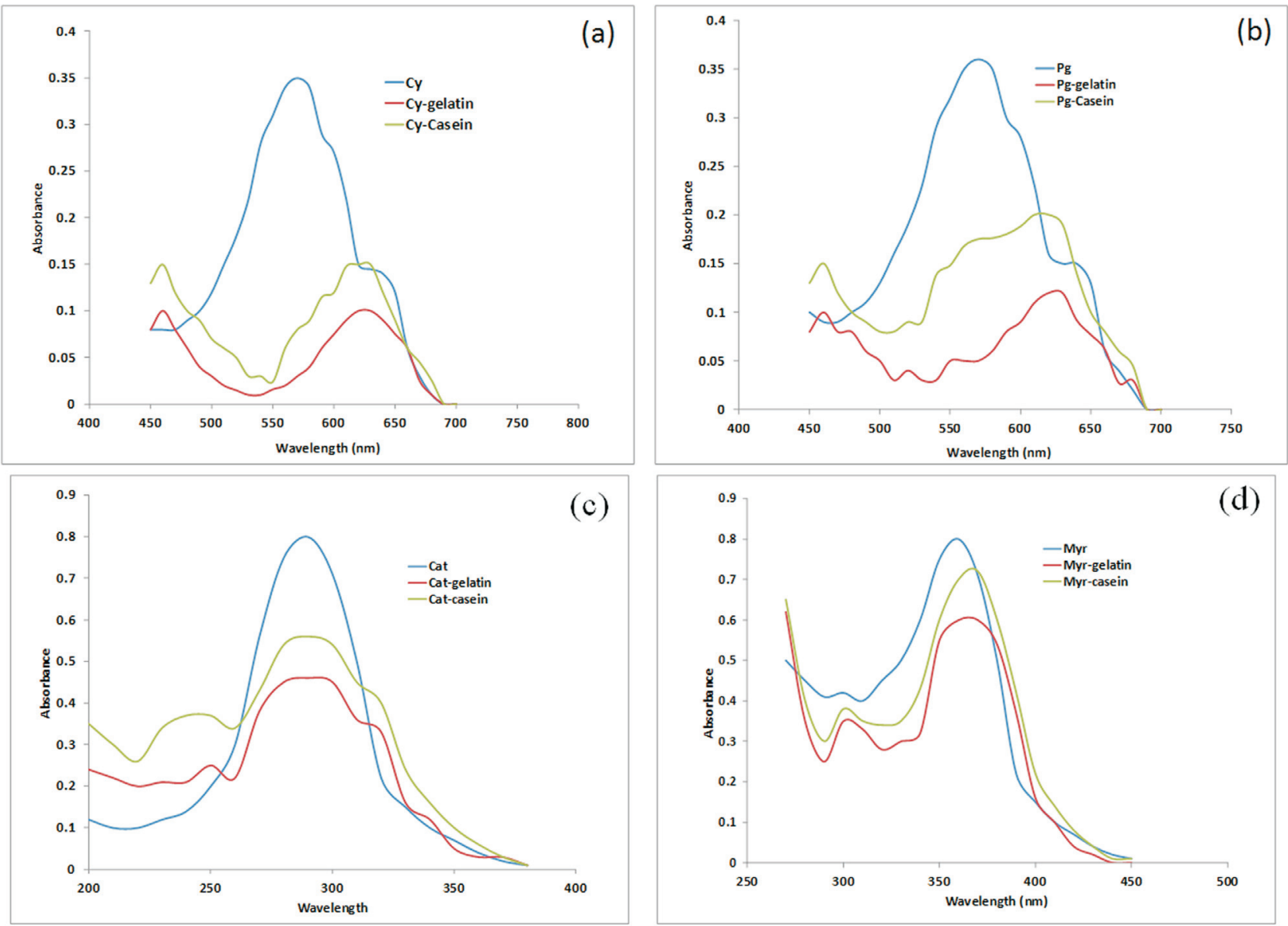

Figure 2 - UV Spectra of flvonoid-gelation and flavonoid-casein complexes (a) pure cyanidin (Cy) and complexes (b) pure pelargonidin (Pg) and complexes (c) pure catechin (Cat) and complexe (d) pure myrecetin (Myr) and complexes. 
Table 2 - Binding constants $(\mathrm{K})$ of the Flavonoid-casein and flavonoid-gelatin complexes at different flavonoid concentrations of $0.25,2.5$, 25 and $250 \mu \mathrm{g} / \mathrm{mL}$ and with a final protein concentration of $250 \mu \mathrm{g} / \mathrm{mL}$. Data expressed as mean \pm standard deviation of 3 replicates. Values within the same column and same row were significantly different $\left.(\mathrm{p}<0.05) .{ }^{*}\right)$ means no significant difference.

\begin{tabular}{lcc}
\hline Flavonoids & \multicolumn{2}{c}{ Binding constants (K) for F-P complexes $\left(\mathrm{M}^{-1}\right)$} \\
\cline { 2 - 3 } & Casein & Gelatin \\
\hline Cyanidin & $5.0 \pm 0.56 \times 10^{7}$ & $6.2 \pm 0.45 \times 10^{7}$ \\
Pelargonidin & $4.1 \pm 0.54 \times 10^{7}$ & $5.1 \pm 0.53 \times 10^{7}$ \\
Catechin & $2.4 \pm 0.23 \times 10^{6}$ & $3.2 \pm 0.21 \times 10^{6}$ \\
Myrecetin & $1.2 \pm 0.09 \times 10^{5^{*}}$ & $2.0 \pm 0.05 \times 10^{5}$ \\
Kaempferol & $1.2 \pm 0.07 \times 10^{5 *}$ & $2.5 \pm 0.04 \times 10^{5}$ \\
\hline
\end{tabular}

the amide group in proline is replaced by a $\mathrm{CH}_{2}$ group and hence it is unable to act as a hydrogen bond donor, it is a very good hydrogen bond acceptor and it is this property which causes them to possess more affinity for molecules with a greater degree of hydroxylation.

Though the activities of free catechin and myrecetin were higher compared to pelargonidin, cyanidin and kaempferol yet the decline in activity of catechin and myrecetin due to complexation with casein and gelatin was more compared to others (Table 2 ) which supports the fact that degree of hydroxylation in $\mathrm{B}$ ring of the flavonoids is not only one of the major factors determining the antimicrobial activity but also one of the important criteria of predicting the binding affinity of the flavonoids for PRPs.

The study may be helpful in predicting, formulating and designing the antimicrobial drugs with maximum potential by elucidating the probable losses of the effective concentrations of the antimicrobial agents

\section{References}

Arts MJ, Haenen GR et al. (2001) Masking of antioxidant capacity by the interaction of flavonoids with protein. Food Chem Toxicol 39:787-791.

Carmona A, Borgudd L et al. (1996) Effect of black bean tannins on in vitro carbohydrate digestion and absorption. J Nutr Biochem 7:445-450.

Charlton AJ, Baxter NJ et al. (2002) Polyphenol/peptide binding and precipitation. J Agric Food Chem 50:1593-1601.

Chauhan A, Gupta S, Mahmood A (2007) Effect of tannic acid on brush border disaccharide in mammalian intestine. Indian $\mathrm{J}$ Exp Biol 45:353-358.

Feng GH, Richardson M et al. (1996) $\alpha$-amylase inhibitors from wheat: Amino acid sequences and patterns of inhibition of insect and human $\alpha$-amylases. Insect Biochem Mol Biol 26:419-426.

Ferrazzano G, Amato I et al. (2011) Plant Polyphenols and Their Anti-Cariogenic Properties: A Review. Molecules 16:1486-1507.

Hagerman AE, Butler LG (1981) The specificity of proanthocyanidin-protein interactions. J Biol Chem 256:4494-4497.
Hara Y, Honda M (1990) The Inhibition of $\alpha$-Amylase by Tea Polyphenols. Agric Biol Chem 54:1939-1945.

Hasni I, Bourassa P et al. (2011) Interaction of milk $\alpha$ - and $\beta$-caseins with tea polyphenols. Food Chem 126:630-639.

He Q, Lv Y et al. (2007) Effects of tea polyphenols on the activities of $\alpha$-amylase, pepsin, trypsin and lipase. Food Chem 101:1178-1182.

Heim KE, Tagliaferro AR et al. (2002) Flavonoid antioxidants: chemistry, metabolism and structure-activity relationships. J Nutr Biochem 13:572-584.

Kanakis CD, Tarantilis PA et al. (2006) Antioxidant flavonoids bind human serum albumin. J Mol Struct 798:69-74.

Kawai K, Tsuno NH et al. (2003) Epigallocatechin gallate, the main component of tea polyphenol, binds to CD4 and interferes with gp120 binding. J Allergy Clin Immunol 112:951957.

Khan N, Mukhtar H (2007) Tea polyphenols for health promotion. Life Sci 81:519-533.

Kuroda Y, Hara Y (1999) Antimutagenic and anticarcinogenic activity of tea polyphenols. Mutat Res 436:69-97.

Lu Y, Bennick A (1998) Interaction of tannin with human salivary proline-rich proteins. Arch Oral Biol 43:717-728.

Luck G, Liao H et al. (1994) Polyphenols, astringency and proline-rich proteins. Phytochemistry 37:357-371.

McDougall GJ, Kulkarni NN et al. (2009) Berry polyphenols inhibit pancreatic lipase activity in vitro. Food Chem 115:193-199.

Mehansho H, Butler LG et al. (1987) Dietary Tannins and Salivary Proline-Rich Proteins: Interactions, Induction, and Defense Mechanisms. Annu Rev Nutr 7:423-440.

Naz S, Ahmad S et al. (2006) Antibacterial activity directed isolation of compounds from Onosma hispidum. Microbiol Res 161:43-48.

Naz S, Siddiqi R et al. (2007) Antibacterial activity directed isolation of compounds from Punica granatum. J Food Sci 72:341-345

Pace CN, Vajdos F et al. (1995) How to measure and predict the molar absorption coefficient of a protein. Protein Sci 4:2411-2423.

Ramassamy C (2006) Emerging role of polyphenolic compounds in the treatment of neurodegenerative diseases: a review of their intracellular targets. Eur J Pharmacol 545:51-64.

Serafini M, Bugianesi R et al. (2003) Plasma antioxidants from chocolate. Nature 424:6952.

Siddiqi R, Naz S et al. (2011) Antimicrobial activity of the polyphenolic fractions derived from Grewia asiatica, Eugenia jambolana and Carissa carandas. International Journal of Food Science \& Technology 46:250-256.

Stephanos JJ (1996) Drug-protein interactions: Two-site binding of heterocyclic ligands to a monomeric hemoglobin. J Inorg Biochem 62:155-169.

Tenore GC, Basile A et al. (2011) Antioxidant and antimicrobial properties of polyphenolic fractions from selected Moroccan red wines. J Food Sci 76:1750-3841.

Waterhouse AL (2001) Determination of Total Phenolics. Current Protocols in Food Analytical Chemistry. John Wiley \& Sons, Inc.

Williamson MP (1994) The structure and function of proline-rich regions in proteins. Biochem J 297:249-260. 
Zhang L, Li J et al. (2010) Inhibitory effect of raspberries on starch digestive enzyme and their antioxidant properties and phenolic composition. Food Chem 119:592-599.
Zhong W, Wang Y et al. (2004) The interaction of human serum albumin with a novel antidiabetic agent-SU-118. J Pharm Sci 93:1039-1046.

Associate Editor: Nilton Erbet Lincopan Huenuman

All the content of the journal, except where otherwise noted, is licensed under a Creative Commons License CC BY-NC. 